\title{
Interprofessional spanning and building boundaries when supporting potential embryo donors to stem cell research
}

\begin{abstract}
When patients undergo fertility treatment, it is likely that a surplus of embryos will be created. The existence of these surplus embryos creates responsibilities for the clinics where they are stored and for the people who own them. Since 2001, the owners of the surplus embryos in the UK have the option to donate them to be used in stem cell research (SCR). This development has generated a new population - potential embryo donors to SCR - who have unique support needs as they are neither fertility patients nor donors. However, little is known how lay and professional stakeholders associated with fertility treatment and SCR have conceptualised the support needs of potential embryo donors to SCR or have responded to the additional task once the option became available. In this paper, we draw on Gieryn's concept of boundary-work to explore how the emergence of donating embryos to SCR has provided opportunities for embryologists, counsellors and scientists to shift, adapt or confirm their roles, knowledge base and areas of expertise. We present a thematic analysis of 21 in-depth, semi-structured interviews conducted between September 2006 and January 2007 with UK lay and professional stakeholders associated with fertility treatment, and SCR. We conclude with reflections on the implications this boundary-work has for those contemplating donating embryos to SCR, and the care they receive when making their decision. Such insights are pertinent given the current policy and practice discussions led by the National Donation Strategy Group to improve the care of donors in the UK.
\end{abstract}

\section{Introduction}

In this paper, we explore how lay and professional stakeholders associated with fertility treatment and SCR discussed the support needs of potential embryo donors in light of the introduction of the option to donate embryos to SCR. In doing so, we highlight the discursive boundary-work (Gieryn, 1983) conducted by, or on behalf of counsellors, embryologists, and 
scientists, with the purpose of retaining or establishing their authority, and protecting and reinforcing their areas of expertise. We will conclude with reflections on the implications this boundary-work has for those contemplating donating embryos to SCR, and the care they receive when making their decision. Such insights are pertinent given the current policy and practice discussions led by the National Donation Strategy Group, set up in 2012 by the Human Fertilisation and Embryology Authority (HFEA), to improve the care of donors in the UK (HFEA, 2012a; 2012b).

\section{Background}

When patients undergo fertility treatment, it is likely that a surplus of embryos will be created. The majority opt to store these surplus embryos, which creates responsibilities for the clinics where they are stored and for the people who own them. Each year, the owners of the surplus embryos are contacted by the clinic to ask if they wish to continue storing the embryos, or dispose of them, or donate to another couple to be used in fertility treatment (Provoost et al, 2010) (see Figure 1).

\section{INSERT FIGURE 1 ABOUT HERE}

Since 2001, the option to donate surplus embryos to be used in SCR was introduced in the UK. The option has proved popular with donors (Provoost, Pennings, De Sutter \& Dhont, 2012) and looks set to emerge as the preferred option (Lomax \& Trounson, 2013). This development however, has generated a new population - potential embryo donors to SCR who have unique support needs as they are neither fertility patients nor donors, are likely to have completed their fertility treatment, and are making decisions about the future of their surplus embryos. 
The care needs of potential embryo donors to SCR

Recent studies describing the care needs of potential embryo donors to SCR have highlighted their concern for how the research is conducted, the potential fate of their embryos and reassurance that their embryos will not be used in reproductive treatment, or human cloning (Samorinha, Pereira, Machado, Figueiredo \& Silva, 2014; Jonlin, 2015).

Therefore it has been recommended that health professionals recognise their responsibilities towards potential embryo donors to SCR by "providing accurate and timely information in accordance with [their] needs" (Samorinha et al, 2014: 653). Yet, this can be complicated as potential embryos donors to SCR are unlikely to be having fertility treatment and therefore no longer attending clinics. In practice, therefore, it is possible to make the final decision to donate embryos to SCR in the UK without any contact with nurses, clinicians, scientists, counsellors or embryologists (see Figure 1).

\section{Whose role is it to care anyway?}

Previous studies have highlighted potential embryo donors' desire for assistance from counsellors when deciding the future of their embryos remaining after treatment (Provoost et al, 2010). In practice, however, nurses or scientists have been more frequently approached, and embryologists have been depicted as alleviating concerns that embryo owners might have about donating to SCR by providing advice and information (van Zyl, van Dyk \& Niemandt, 2005). Despite their contribution acknowledged in the literature, there appears to be a vulnerability surrounding the roles of counsellors and embryologists, which is reinforced when they are portrayed as subordinate occupations in relation to clinicians. High profile clinicians have voiced the need for embryologists' services to be given the full recognition they deserve, and a move away from embryologists being viewed as "adjuncts 
to clinicians" (Edwards \& Ahuja, 2001: 71). Similarly, counsellors have been presented as reliant upon clinicians, particularly to encourage the uptake of counselling by patients (Boivin, Scanlan \& Walker, 1999; Monach, 2003). Yet, Appleton (2005), himself a counsellor, claimed that counsellors should be independent of fertility treatment teams in order to support the patients' views and needs within the clinical setting. It is clear from the literature that counsellors hold an awkward position within fertility treatment teams, which is exacerbated by other occupational groups describing their roles as involving counselling patients, prompting counsellors to set definitional boundaries around 'counselling' and defend counselling within a counsellor's remit (Appleton, 2005).

The depictions of counsellors and embryologists are in sharp contrast to the partnerships forged between clinicians and scientists as a result of the introduction of the option to donate embryos to SCR. Whilst early studies on fertility treatments typically focused upon the role and status of clinicians (Franklin, 1990), more recently, the role of the scientist has become of interest (Ehrich, Williams, Rosamund, Sandall \& Farsides, 2006; Wainwright, Williams, Michael, Farsides \& Cribb, 2006). Researchers have focused on the relationships that SCR has initiated between scientists and clinicians (Parry, 2006), and the amalgamation of stem cell laboratories and fertility clinics into single facilities (Franklin, 2006) creating a sense of parity between these two occupational groups and the possibility for collaboration between those operating within clinics and laboratories.

\section{Interprofessional collaboration and boundary work}

Collaboration between practitioners is deemed essential in order to provide good quality care as no one occupational group can meet all a patient's needs (Freeth, 2001; Reeves, 
Lewin, Espin \& Zwarenstein, 2010). Yet, collaboration is seldom instigated by health professionals, and instead is avoided (Wackerhausen, 2009). Such a response may result from the need for professional boundaries to be transcended leading to a loss of autonomy for the health professionals involved (Freeth, 2001; D'Amour, Ferrada-Videla, Rodriguez \& Beaulieu, 2005). Therefore, a complex relationship can exist between different occupational groups involved in the care of patients. This is caused in part by their occupation-specific vision of the patients and the services that they are required to provide ( $D^{\prime}$ Amour et al, 2005) as well as the power imbalance that can exist between healthcare providers in an interprofessional environment (Gachoud, Albert, Kuper, Stroud \& Reeves, 2012). In order to facilitate collaboration across these professional boundaries, informal processes may be developed for the interactions between the professionals of different occupations. These processes serve the patients' needs through the enabling of collaboration across the boundaries, and also serve the professionals' needs through the maintenance of boundaries that continue to ensure their professional autonomy (Heldal, 2010).

The building and establishing of boundaries is a means to protect professional authority, power and status (Fournier, 2000), usually in response to the emergence of novel or potential adoption of additional tasks (e.g. Goodwin, Pope, Mort \& Smith, 2005; Machin, Brown \& McLeod, 2012). Boundary-work as described by Gieryn (1983) entails one occupational group attributing characteristics to another occupational group in order to distinguish themselves favourably. Hierarchies can form with some occupational groups perceived to hold a more or less dominant position according to whether their work activities are portrayed as 'scientific' or 'non-scientific' (Gieryn, 1983) or being more or less 'patient-centred' (Timmons \& Tanner, 2004; Gachoud et al, 2012). For Gachoud et al (2012), 
by achieving predominance in these hierarchies, occupational groups can increase their symbolic status with other groups. As a result, such characteristics can be used to define a profession, demonstrate how it differs to other occupational groups, and ultimately influence how the work practices of others are interpreted (Timmons \& Tanner, 2004; Swedlow, 2007; Stephens, Atkinson \& Glasner, 2008). Importantly, this discursive boundarywork can highlight professional 'territories of care' - each with their own priorities and patterns of working (Hardey, Payne, Powell, Hawker \& Kerr, 2001) and distinct areas of knowledge and practice (Langan-Fox \& Cooper, 2014). Knowledge is deemed central to professional control (Abbott, 1988) and therefore battles can form as occupational groups attempt to claim or maintain their jurisdiction and expertise (Covaleski, Dirsmith \& Rittenberg, 2003). So, for some, boundary-work can have a detrimental effect as professionals are viewed as specialists, with a very narrow area of expertise (Haug, 1973; 1988), whilst others claim it can enhance the status of a subordinate occupational group as they grow their area of expertise by adopting tasks not previously in their remit (Mesler, 1991; Edmunds \& Calnan, 2001). In essence, discursive boundaries can influence and reflect power dynamics and relations between occupational groups (Tellioglu \& Wagner, 2001; Gesler, Bell, Curtis, Hubbard \& Francis, 2004) thereby providing insight into the 'ambivalences' or 'strains' between them (Gieryn, 1983).

Boundary spanning is thought to emerge at times when complex and interdependent issues arise across real and socially constructed boundaries, and in the context of healthcare, when there are gaps in service provision or needs unmet (Williams, 2011). So, in the case of embryo donation for SCR, as a technique it spans the boundaries of fertility clinics and research laboratories, as well as generating the task and care responsibility of supporting 
potential embryo donors to SCR in their decision-making. Potential embryo donors sit at the intersections of fertility clinics and research laboratories, and professional groups from these two worlds, such as embryologists, counsellors and scientists are brought together within the context of meeting potential embryo donors to SCR needs. Therefore, those involved in supporting potential embryo donors to SCR are also likely to span these boundaries "to garner support, resources, or information needed..." (Wilemon, 2014: 230) and act as a link between the boundaries (Peng \& Sutanto, 2012). In order to span these boundaries successfully, instilling trust is essential (Williams, 2011; Kroeger \& Bachmann, 2014) as well as having an appreciation for the different cultures, motivations, and practices of a wide range of occupational groups (Williams, 2011; 2013). Those spanning boundaries can develop niche areas of expertise, knowledge and experience (Williams, 2013), shifting them into a position of power and influence (Aldrich \& Herker, 1977). Yet, few have explored how embryologists, counsellors and scientists have responded to the introduction of the option to donate embryos to SCR. In particular, how the emergence of SCR has provided opportunities for embryologists, counsellors and scientists to shift, adapt or confirm their roles, knowledge base and areas of expertise.

\section{Methods}

An active interview approach was adopted which permits researchers to draw on their background knowledge of a topic when designing a study (Holstein \& Gubrium, 1995).

\section{Sampling and recruitment}

In this study, potential participants were highlighted through reviews of: the scientific and medical literature, websites of UK organisations, and policy documentation, events that 
focused specifically on matters relating to embryo donation. Therefore approximately 20 potential participants were identified according to the following inclusion criteria: located within the UK at the time of study and English-speaking; played a prominent role in the historical development of embryo donation in the UK and/or actively involved in the embryo donation process in the UK at time of study.

The number of potential participants identified was limited due to the small number of clinics in the UK who offered the option to donate embryos to SCR. The potential participants identified were lay and professional stakeholders associated with fertility treatments or SCR i.e. clinicians, scientists, potential embryo donors, support group representatives, regulators and policy makers.

Holstein and Gubrium (1995) argue the sampling process can extend into the data collection phase in order to respond to the direction of the research. The aim is not to gather a representative sample, since social constructionists (Berger \& Luckmann, 1966) are not striving to unearth one true objective reality, but instead understand reality as created through meanings (Kvale, 1996). Therefore, multiple accounts are available, enabling a multiplicity of voices to be included in studies. Those who participated in the project made recommendations of potential participants, such as the professional stakeholders counsellors, embryologists, and fertility nurses, who were followed up when feasible.

Participants from clinics, laboratories, and the policy communities were recruited via emails promoting the project. Participants who had used fertility treatment were recruited through fertility and donor support groups who agreed to advertise the 
project to their members, and place adverts on their websites or in their newsletters. This approach was preferred over recruiting through clinics as it enabled targeted recruitment of the hard to reach group - (potential) embryo donors. Of the approximately 20 potential participants initially approached, two declined to participate. A further five potential participants were initially approached as recommended by those interviewed, of which two did not respond to recruitment emails.

Data collection

A total of 21 face-to-face interviews were conducted between September 2006 and January 2007 with lay and professional stakeholders associated with assisted conception techniques and SCR (see Table 1).

\section{INSERT TABLE 1 ABOUT HERE}

Whilst the number of participants from each sub-group was small, it was not the intention to interview the individual as a representative of that occupational group or community, but rather to elucidate the points made by other participants.

Each interview lasted between 1 and 2 hours and were recorded in full. The interviews were semi-structured in nature to provide rich and in depth data, and an interview guide was used to access participants' experiences, views, and perceptions of the option to donate embryos to SCR. This allowed the participant and the interviewer the freedom and flexibility to follow up topics that might not initially be on the interview guide (Holstein \& Gubrium, 1995).

Data analysis 
All the interview recordings were transcribed in full and were coded for themes (Braun \& Clarke, 2006), using the qualitative data package, Nvivo7. Initially, the codes were based upon very broad themes relating to the processes and practices surrounding embryo donation e.g. 'Informed consent', 'Compulsory counselling'. These broad codes were achieved through reviews of the scientific and medical literature, websites of UK organisations, policy documentation, and events. Coding at this high level brought to the fore the roles of different occupational groups within the embryo donation process and practices, and consequently new codes emerged from the data e.g. 'Counsellor's role', 'Embryologist's role'. During the coding phase of the data, it was apparent that individual participants adopted multiple identities and positioned themselves differently throughout the interview (Holstein \& Gubrium, 1995) by using statements “...as an infertility counsellor..." or "....as someone who knows what fertility treatment is like....". This observation influenced the language used in the coding structure, to reflect the social constructionists' treatment of data as accounts, rather than a factual representation of a phenomenon. So, the code of 'Counsellor's role' was amended to 'Portrayal of counsellor's role', with a variety of lower level codes within it i.e. 'Infertility counselling only', 'Patient perspective'. Existing codes became more refined with each reading of the transcripts, such as 'Embryo donation' being divided into 'Embryo donation for infertility purposes' and 'Embryo donation for research purposes'. The analysis was therefore an iterative process taking into account any 'unexpected issues' (Seale \& Kelly, 1998) that had not been previously considered by the researcher, but emerged during the reading of the data, leading to further refinement of the codes. Throughout the project, data transcripts, data extracts within specific codes, and analytical summaries were read by, and discussed with, 
colleagues on a regular basis, which informed the coding process, and ensured the quality of the data analysis.

\section{Ethical considerations}

Procedurally, ethical considerations extended to gaining approval from three sources: the University institution, the NHS, and each NHS Trust depending upon where participants were based. Every participant was sent a consent form and a participant information sheet via email before the interview took place to ensure they were aware what the interview involved and give them the opportunity to ask any questions regarding the study or their participation. At the start of every interview, each participant read and signed a consent form. It was explained to participants that they could withdraw their consent at any point throughout the interview. In the dissemination phase, limited demographic details of the participants are provided to respect participants' anonymity. Embryo donation within the UK comprises of a small community, and it is possible that some participants could be identified, depending on the amount of demographic details provided.

\section{Results}

In this section, we report on three prominent themes emerging from the data. To put the three themes into context, participants were asked about the process of donating to SCR and how it should be organized, in particular the information provided and potential embryo donors' access and availability to the information. The first theme sees participants positioning themselves favourably, or others unfavourably, based upon an occupational group's frequent contact with either embryos or patients during their daily tasks. The second theme builds on the findings 
described so far by counsellors and scientists constructing boundaries around their own and each other's areas of expertise based on their contact with patients or embryos. Areas of expertise are divided into 'counselling' (for counsellors) or 'scientific' (for scientists) matters, with deciding to donate to SCR being firmly located within scientists' area of expertise. Finally, in the third theme, participants maneuver one occupational group - the embryologist - into a position whereby they span the constructed boundaries set out in the previous two themes in order to fulfill the unmet need of supporting potential embryo donors to SCR. Embryologists are described as working at the intersections of the constructed boundaries described so far, thereby enabling this occupational group to expand their influence and power base.

\section{Advocates and Champions}

During discussions on supporting potential embryo donors to SCR in their decision-making some participants positioned themselves favourably as a patient advocate:

“Embryos are not property in the UK, so you can't own them, but nevertheless, those people whose gametes were used to produce them have an interest, and that interest is exercised through their consent...You can place conditions on any consent you give and you can make those as restrictive, as prejudiced, as you want to. Consent is the cornerstone of legislation and the ability to place conditions at your discretion on consent is absolutely fundamental to that." (Regulator)

"I've no problem with donating embryos. That's the couple's choice. Whether it's for research or for treatment, just so long as it's an informed choice. It's very important that they are aware of the [specific] research [studies]. They want to know the results of the research that they'd donated to, and I think that's actually fair enough." (Support Group)

Or an embryo champion:

"Embryos should be used for the best possible research. So I'm hoping that the researchers will use a relatively precious commodity for the best possible research and the most promising research. And it's not for Politicians to say what that is. The 
Howden principle says that research councils and research funders decide what projects should be funded." (Regulator)

It is possible the additional task to provide support for potential embryo donors to SCR created an opportunity for some participants to claim new territory and enhance their authority and status within fertility treatment and SCR communities. In order to achieve this, participants tended to construct explicit divides between two occupational groups, which is most apparent in the interviews with counsellors and scientists.

When counsellors discussed their role in the context of people deciding to donate embryos to SCR, they made references to their daily contact with fertility patients, which meant they were able to offer insight into fertility patients' views at clinic meetings. A senior counsellor from a clinic in the North of England claimed she was more accepting of fertility patients' decisions not to donate their embryos and instead take them home, in comparison to the scientists at the same clinic:

"...people should have the right to deal with the embryos how they want and take them home...I think the scientists had to get their heads round this because they thought it was quite bizarre, you know, these people are crackers. I don't think they are" (Counsellor)

In the above interview extract, the building of boundaries is apparent when the counsellor portrayed her role as protecting and promoting patients' rights and choices, and the service she offered as patient-centred. She did this by attributing characteristics to scientists i.e. unable to appreciate patients' decisions to not donate embryos, and questioned patients' decision-making capacity, in order to present counsellors favourably. Arguably, her insight into patients' views meant she did not question their decisionmaking capacity as she understood their decision to take the embryos home. A 
counsellor reinforced this point when she claimed she was able to understand the significance of the embryo for fertility patients, unlike the scientists at her clinic:

"...when the scientists say it's only an embryo. I say it's not to them, the couple. You just watch it because it's everything to people. So I think it's incredibly important. It's not just another embryo" (Counsellor)

In two ways, the counsellor positioned her role in the clinic as advocating the patient's perspective: she referred to fertility patients' views on their embryos and she implied that scientists' frequent contact with embryos during research meant they downplayed the significance of the embryo from a patient's perspective and the resulting decision potential embryo donors had to make. Equally, such positioning by the counsellor influenced how the work activities of scientists were portrayed in particular, scientists' contact with embryos during their research constructed the scientist's role as the embryo champion. To some extent, scientists embraced the construction of their role as embryo champion during their interviews, usually when the matter of disposing of embryos arose. For the scientists, disposing of embryos - be they "taken home" or "thrown in the bin" - meant the embryos were wasted. Instead, the donation of embryos saved them from going to waste, even though the embryos were destroyed when used in research as a scientist explained:

"...the fact that the embryo has to be killed, I don't have a problem with that...the alternative is they go in the bin...A lot of the ways in which they're prepared for research, in other words killed, is exactly the same biological process as would happen if they were discarded. It's no different" (Scientist)

Consequently, for the scientists interviewed, the promotion of the donation of embryos was perceived as acting in the best interests of the embryos - hence the embryo champion. Yet, the scientists were also keen to acknowledge that people making the decision to donate their embryos or not had support requirements, which suggested they 
recognised the significance of the embryo for potential embryo donors, and challenged the portrayal of their role as solely being an embryo champion:

"....at the point at which they have to make a decision as to what happens to those embryos, they are reminded that if they need to seek further counselling they can contact anybody at the clinic to discuss it...If they are left in any doubt whatsoever, they should come back to us and ask all the questions they need to make an appropriate decision." (Scientist)

“Counselling isn't absolute, but we would encourage all couples who [plan to] donate their embryos, to go along and talk through all their issues with counsellors..... think counselling in its widest sense in terms of the counselling for support and understanding is very useful and if people want to go back and talk to the counsellors afterwards, I would think that's a very good idea." (Scientist)

In essence, the scientists also wished to demonstrate their ability to have insight into the potential embryo donors' perspective, and for their work to be perceived as 'patientcentred'.

\section{Expertise}

To some extent, participants considered who was suitable to assist potential embryo donors with their decision-making based on how participants viewed counsellors', scientists' and embryologists' areas of 'expertise'. The contact counsellors, scientists and embryologists had with fertility patients and/or embryos formed the basis for their areas of expertise. Yet, the designated areas of expertise were rarely made explicit by participants, and instead were usually implied. For example, a senior counsellor from a clinic in the North of England constructed 'scientific' and 'counselling' areas of expertise around her and scientists' roles:

"I wouldn't comment on the scientific stuff because I don't understand it. And I don't want the scientists to comment on the counselling bit either" (Counsellor).

In the quote, the counsellor suggested she did not consider 'scientific' matters within her 
area of expertise. Yet such a distinction enabled her to reinforce the boundaries surrounding her own knowledge and practice - that of counselling - when she stated she did not consider 'counselling' matters within the area of expertise of scientists. It can therefore be inferred that she considered 'counselling' matters to be within counsellors' area of expertise and 'scientific' matters within scientists' areas of expertise.

It was common for counsellors' and scientists' areas of expertise to be presented by participants as distinct from one another. It suggested that participants did not consider it possible for counsellors and scientists to be considered an expert on 'counselling' and 'scientific' matters. However, it was difficult to ascertain what constituted a 'scientific' or 'counselling' matter, and how participants distinguished between them. That said, it could be inferred how participants understood and interpreted the donation of embryos to SCR process i.e. as a 'scientific' or 'counselling' matter from whom they considered best placed to support potential embryo donors in their decisionmaking.

Support from counsellors, support groups and scientists varied when asked if they thought counsellors should be involved in supporting potential embryo donors in making their decision. A senior representative of a fertility support group argued counsellors were "well-placed" to offer support for potential embryo donors, but claimed mandatory counselling was not the solution, “you can't counsel someone on a mandatory basis, people have to choose" (Support Group). This participant undermined the notion that counsellors were the only source of support, perhaps due to her representing a group that concerned itself with supporting fertility patients, as well as reflecting fertility patients' 
views, and therefore considered itself as a (alternative) source of support. It is also possible that she did not consider the decision to donate embryos to SCR as solely a 'counselling' matter, and therefore not limited to a counsellor's remit.

A counsellor's remit of 'counselling' was also threatened when participants claimed potential embryo donors' support requirements could be fulfilled by interaction with members of the clinical team rather than undertaking counselling,

"Some couples... will talk it through with themselves and with nurses, clinicians, even embryologists...They're quite happy to deal with it on that level; they don't necessarily want to do counseling" (Scientist)

“My consultant [asked] if you've got any embryos that aren't good quality, would you be prepared to use them in research...I did speak to an embryologist about it and he [explained embryo development]" (Potential Embryo Donor)

Interestingly, the scientist and potential embryo donor raised the possibility of clinical team members assisting potential embryo donors in their decision-making, which implicitly moved embryo donation for SCR outside of the constructed boundaries of 'scientific' and 'counselling' matters and experts.

Support groups representatives, regulators, scientists and counsellors stated that members of clinical staff were well-placed to assist potential embryo donors, as long as the decision was made voluntarily and without coercion. Given the discussions included counsellors and scientists, it was assumed that the term 'clinical staff' included fertility nurses, clinicians and embryologists. A participant working at a regulatory body argued it was essential to "remove any kind of conflicts of interests, particularly in relation to patient information and consent" (Regulator). Similarly, a support group representative argued clinical staff should aim to be impartial when discussing embryo donation with potential embryo donors to avoid "a real pressure or a 
drive for SCR" (Support Group). This raised the possibility that the decision-making process of donating embryos to SCR could be interpreted as a 'clinical' matter, with potential embryo donors' needs being met by those with expertise that spanned the constructed boundaries of 'scientific' and 'counselling' matters.

\section{Working at the intersections}

When the matter of meeting the support requirements of potential embryo donors was discussed, the role of the embryologist was portrayed by all participants as operating at the intersections of the discursively constructed role boundaries and areas of expertise of counsellors and scientists discussed previously, and therefore ideally placed to meet this need.

Embryologists were described as being able to offer technical information on SCR, and were therefore considered by potential embryo donors as part of a "counselling team" (see Figure 2). Two potential embryo donors and an embryo donor portrayed their discussions of the above issues with embryologists as providing "peace of mind" (Potential Embryo Donor). For these participants, the need for 'scientific' issues to be addressed when making their decision to donate their embryos or not, was significant. In particular, the demand for technical and specific information relating to embryos used in SCR, such as the "level of research, the invasion, [and] what happens to them" (Embryo Donor), as well as the "obligations about making sure that they [embryos] are only researched on until they reach a stage where they become viable" (Potential Embryo Donor). For some potential embryo donors, part of the decision-making process entailed reassurance that guidelines were followed during SCR, as well as insight into how the 
embryos were used during the research.

\section{INSERT FIGURE 2 ABOUT HERE}

Scientists and counsellors recognised potential embryo donors' requirements for 'scientific' information when making the decision to donate embryos or not. They described how embryologists "work[ed] with" (Scientist) counsellors on information evenings at clinics:

"I get embryologists up to talk if [patients] want to talk about [embryo donation for SCR] in my session and say l'd like to know a bit more" (Counsellor)

The counsellors claimed they lacked a sufficiently in-depth understanding of SCR and therefore lacked the knowledge base to take on the additional task of supporting potential embryo donors in their decision-making. Instead, the counsellors described how they referred the potential embryo donors to embryologists, who were portrayed as able to fill this gap:

"If they're [potential embryo donors] interested I would get an embryologist to talk more if they want to know more...I wouldn't get involved. Basically, I give them very basic stuff: a) we're doing embryo research, b) they can only use the embryos up to 14 days. And if they want to know more I would refer them on" (Counsellor)

In turn, the counsellors' referrals suggested that embryologists had the knowledge base, which enabled them to act in a supporting role, offering both advice and information to potential embryo donors. It is noteworthy that the counsellors referred potential embryo donors to embryologists, as opposed to scientists. It could be a matter of logistics i.e. the scientists might have been located away from the clinic and therefore not physically available to speak to patients. However, from the counsellor's quote, it could be inferred that as embryologists were located within the clinic, and therefore physically removed from where the SCR was conducted, they were perceived as less biased 
towards the donation of embryos for SCR, in comparison to scientists.

Scientists also referred to embryologists' knowledge base which was depicted as informed through embryologists' visits to research laboratories (see Figure 2). These visits were depicted as forming the basis for the interaction between potential embryo donors and embryologists,

"We've had embryologists come over here to see what we're doing. I mean that must help; for them to be able to talk to the patients and say well actually I've been over there and it's really good and I've seen what they do. And that must add confidence as well" (Scientist)

For this scientist, the embryologists' visits to, and contact with, the laboratories where the embryos were used in SCR were seen as allowing them to assist potential embryo donors in their decision-making.

Embryologists embraced this positioning of their role spanning the clinic and laboratory boundaries in order to adopt the additional task of supporting potential embryo donors in their decision-making. Initially, the embryologists created a need for support by describing potential embryo donors as reluctant to engage with the decision-making process:

"An awful lot of couples don't reply to our letters at all. They just ignore them, and that's because they don't want to make a decision on the fate of their embryos. Because some couples regard then as small babies or potential babies. So they let us make the decision, which then has to be to destroy them, which is very unfortunate." (Embryologist)

"[Patients] have potentially 8 or 9 consent forms to do, and that's an awful lot when you're coming for quite a stressful treatment. And when you then consent to research at the end of that, and we only give the research [information] in stages because we feel people get so bombarded, and they consent. They're a bit uncertain about stem cells at the moment, because if there's something in the press about cloning, you find people back off although that's different and we talk to them about it. But they find it's too much to deal with when you get a big explanation." (Embryologist) 
Once a gap was constructed, the embryologists described their work experiences and knowledge base to establish themselves as ideally placed to fulfil this unmet need. Their daily tasks were frequently referred to which meant they were able to offer insights into both fertility patients' perspectives and comment on matters relating to embryos:

"we deal with the gametes - you see patients from a very different angle" (Embryologist)

"the embryologists...spend a lot of their professional lives making embryos in the lab, fertilizing eggs, you know, looking after these embryos growing" (Embryologist)

An embryologist referred to the contact she had with fertility patients when creating the embryos for their treatment, which she claimed formed the basis for good relations with potential embryo donors after their treatment was completed:

"if any patient wants to speak to an embryologist then we are more than happy to go and sit down somewhere quiet and discuss whatever is on their mind with them" (Embryologist)

Equally, embryologists' contact with scientists and counsellors meant they had an appreciation for their different cultures, motivations and practices, in particular the value of embryos from a scientists' perspective - "avoiding embryos going to waste" (Scientist) and the contribution of counsellors - "[the counsellor] makes you think of things sometimes that you haven't" (Embryologist) - when discussing the donation of embryos to SCR. Embryologists $s \mathrm{t} r \mathrm{i}$ v e d t o portray themselves as having "the biggest overview [as they] deal with the patients [and] not just stay in the lab" (Embryologist) in an attempt to challenge any assumptions around their role that might hinder them from being perceived as able to support potential embryo donors in their decision-making.

\section{Discussion}


This study has highlighted that for lay and professional stakeholders associated with fertility treatment and SCR, the additional and novel element of SCR alters who is considered best placed to support potential embryo donors when making their decision to donate or not. Unlike donating embryos to other couples for their fertility treatment, which has been firmly shown to be within counsellors' remit (Machin, 2011), the decisions to donate embryos to SCR is considered outside counsellors' responsibilities. Instead, in line with previous research, it is deemed a matter for embryologists (Eilertsen et al, 2009), and in turn embryologists are viewed in a supporting role (van Zyl et al, 2005).

This study has highlighted the desire by those within fertility treatment and SCR communities for their role and approach to be perceived as 'patient-centred'. Two very distinct territories of care emerged with counsellors' territory with patients as their priority, and patient insights as their distinct area of knowledge (Hardey et al, 2001; Langan-Fox \& Cooper, 2014). Equally, scientists were keen to depict potential embryo donors as requesting support from members of clinical teams, to avoid counsellors being perceived as the only source of assistance. Such positioning by the scientists undermines and challenges the counsellors' territory of care and illuminates the wider battles for expertise and authority taking place surrounding potential embryo donors (Covaleski, et al, 2003). This suggests there is a power or influence that derives from being associated with 'patient-centred' care (Gachoud et al, 2012). If translated into practice, this eagerness for patient-centredness could go some way to potential embryo donors' voice influencing how services and their decision-making needs are met and put pressure for a collaborative approach to be adopted (Freeth, 2001). 
Collaboration was avoided by the counsellors and scientists in this study (Wackerhausen, 2009). The boundary-work highlighted the professional strain between the counsellors and scientists that emerged once the option to donate embryos to SCR was introduced in the UK (Gieryn, 1983). Counsellors attempted to avoid a loss of power by restricting the remits of both counsellors and scientists - 'scientific' or 'counselling' matters - so that there was a sharing of authority, but not overlapping, between the two occupational groups (Fournier, 2000). In essence, counsellors and scientists were reluctant for their professional boundaries to be blurred and for their autonomy to be reduced (Freeth, 2001; D'Amour et al, 2005).

Consequently, a complex relationship was discursively constructed between counsellors and scientists when discussing meeting the care needs of potential embryo donors to SCR. Neither occupational group wished to take on the additional task of supporting potential embryo donors to SCR, nor did they wish for each other to take on the role. Such boundarywork suggests that counsellors and scientists felt threatened, perhaps as a result of the amalgamation of fertility clinics and research laboratories (Franklin, 2006), which limited the possibility for collaborations to forge between the two occupational groups when supporting potential embryo donors to SCR in their decision-making (D'Amour et al, 2005). In practice then, this lack of collaboration could negatively affect the quality of care received or even make getting support challenging for potential embryo donors to $\mathrm{SCR}$, with no one accepting responsibility for the task, or displaying a reluctance to share the role (Freeth, 2001; Reeves et al, 2010). 
Embryologists were presented as spanning the discursively constructed boundaries of clinics and laboratories and acting as the link between them (Peng \& Sutanto, 2012). Embryologists were also constructed as holding a niche knowledge base given their experiences with fertility patients and embryos, and insights into clinics and laboratories (Williams, 2013; Wilemon, 2014) and therefore it was considered that potential embryo donors could trust the embryologists when deciding to donate embryos (Williams, 2011; Kroeger \& Bachmann, 2014). Embryologists accepted this portrayal of their role and adopted the additional task of supporting potential embryo donors as it enabled them to expand their influence and power base (Aldrich \& Herker, 1977). Arguably, neither scientists nor counsellors felt threatened by embryologists, although the unstructured and ad-hoc nature of embryologists' involvement in assisting potential embryo donors to SCR was emphasised during their interviews i.e. referrals to embryologists, visits to laboratories, information evenings, and talks with potential embryo donors. Such informality surrounding embryologists' contributions to assisting potential embryo donors to SCR softens the potential threat of the influence and power that embryologists could acquire by taking on this new responsibility. In effect, the needs of the potential embryo donors were met through such informal processes, whilst also maintaining and protecting the boundaries of counsellors' and scientists' professional authority (Heldal, 2010) meaning interprofessional collaboration was averted (Wackerhausen, 2009). For practice, such informal processes could make accessing support difficult for potential embryo donors when making their decision. Instead, a more formalised support system available in clinics, through explicitly offering a referral system in which embryologists are involved could benefit potential embryo donors, as well as embryologists by formally acknowledging their contribution to the decision-making process within their job remit. The resulting clarity surrounding embryologists' responsibilities and 
tasks open the possibility for improved collaboration (Pape, Thiessen, Jackson \& Hansen, 2013) and therefore better care provided.

It is a limitation that the findings from this study a re based on a small sample size, across multiple stakeholder groups, recruited from a small number of sites based in the UK. Even though the interviews conducted with the small number of participants were indepth and therefore generated rich data, the generalisability of the findings is restricted. Furthermore, the views expressed in this paper are unlikely to reflect those from similar stakeholder groups. However, as stated above, the aim of the project was not to unearth one true objective reality that required a representative sample.

\section{Concluding comments}

As the option to donate embryos to SCR has proved a popular choice with potential embryo donors, there is a pressing need to focus upon the complex support requirements of potential embryo donors, and arrange services accordingly. As has been identified with gamete donors, the care needs of potential embryo donors should be viewed as extending beyond the clinical environment, and that decision-making assistance is part of the follow-up care available for (potential) donors and patients. The support needs of potential embryo donors when making their decision should be recognized in their own right, and the support available to them formalised. In turn, the contribution that embryologists make to supporting potential embryo donors in their decision-making needs to be widely acknowledged. 


\section{Acknowledgements}

We would like to thank all the participants who generously gave up their time to meet with her. She would also like to acknowledge the support she received from Professor Anne Kerr, and Dr Colin Lindsay when developing the idea for this paper, and the invaluable comments from the reviewers of this paper

\section{Declaration of Interest}

The authors report no declarations of interest.

\section{Funding}

The research was funded by a Wellcome Trust Biomedical Ethics Grant awarded to Dr Machin (no.:075300/Z/04/Z).

\section{References}

Abbott, A. (1988). The System of professions: an essay on the division of expert labour. London: The University of Chicago Press.

Aldrich, H., \& Herker, D. (1977). Boundary spanning roles and organization structure. Academy of Management Reviews,2(2), 217-230.

Appleton, T. (2005). The distress of infertility: some thoughts after 22 years of infertility counseling. In P.R. Brinsden (Ed.), Textbook of IVF and assisted reproduction: The Bourn Hall guide to clinical and laboratory practice, $\left(3^{\text {rd }}\right.$ ed.). London: Taylor and Francis.

Berger, P.L. \& Luckmann, T. (1966). The social construction of reality: a treatise in the sociology of knowledge. New York: Doubleday.

Boivin, J., Scanlan, L.C., \& Walker, S.M. (1999). Why are infertile patients not using psychosocial counseling. Human Reproduction, 14(5), 1384-1391.

Braun, V., \& Clarke, V. (2006). Using thematic analysis in psychology. Qualitative Research in Psychology, 3(2), 77-101.

Covaleski, M.A., Dirsmith, M.W., \& Rittenberg, L. (2003). Jurisdictional disputes over professional work: the institutionalization of the global knowledge expert. Accounting Organizations and Society, 28(4), 323-355.

D'Amour, D., Ferrada-Videla, M., Rodriguez, L.S.M., \& Beaulieu, M.-D. (2005). The conceptual basis for interprofessional collaboration: core concepts and theoretical frameworks. Journal of Interprofessional Care, 19(sup1), 116-131. 
Edmunds, J., \& Calnan, M.W. (2001). The reprofessionalisation of community pharmacy? An exploration of attitudes to extended roles for community pharmacists amongst pharmacists and general practitioners in the United Kingdom. Social Science \& Medicine, 53(7), 943-955.

Edwards, R.G., \& Ahuja, K.K. (2001). Legal cases spell big trouble and great opportunities for IVF embryologists. Reproductive BioMedicine Online, 2(1), 70-71.

Ehrich, K., Williams, C., Rosamund, S., Sandall, J., \& Farsides, B. (2006). Social welfare, genetic welfare? Boundary-work in the IVF/PGD clinic. Social Science \& Medicine, 63(5), 1213-1224.

Eilertsen, M.E.B., Kristiansen, K., Reinfjell, T., Rannestad, T., Indredavik, M.S., \& Vik, T. (2009). Professional collaboration - support for children with cancer and their families - focus group interview - a source of information and knowledge - professionals' perspectives. Journal of Interprofessional Care, 23(4), 355-368.

Franklin, S. (1990). Deconstructing desperateness: the social construction of infertility in popular representations of new reproductive technologies. In M. McNeil, I. Varcoe, \& S. Yearley (Eds.), The new reproductive technologies. London: Macmillan Press.

Franklin, S. (2006). Embryonic economies: the double reproductive value of stem cells. Biosocieties, 1(01), 71-90.

Freeth, D. (2001) Sustaining interprofessional collaboration. Journal of Interprofessional Care, 15(1), 37-46.

Fournier, V. (2000). Boundary work and the (un)making of the professions. In N. Malin (Ed.), Professionalism, boundaries and the workplace. London: Routledge.

Gachoud, D., Albert, M., Kuper, A., Stroud, L., \& Reeves, S. (2012) Meanings and perceptions of patient-centeredness in social work, nursing and medicine: $A$ comparative study. Journal of Interprofessional Care, 26(6), 484-490.

Gesler, W., Bell, M., Curtis, S., Hubbard, P., \& Francis, S. (2004). Therapy by design: evaluating the UK hospital building program. Health \& Place, 10(2), 117-128.

Gieryn, T.F. (1983). Boundary-work and the demarcation of science from non-science: strains and interests in professional ideologies of scientists. American Sociological Review, 48(6), 781-795.

Goodwin, D., Pope, C., Mort, M., \& Smith, A. (2005). Access, boundaries and their effects: legitimate participation in anaesthesia. Sociology of Health \& IIIness, 27(6), 855-871.

Hardey, M., Payne, S., Powell, J., Hawker, S., \& Kerr, C. (2001). Professional territories and the fragmented landscape of elderly care. Journal of the Royal Society for the Promotion of Health, 121(3), 159-164.

Haug, M.R. (1973). Deprofessionalization: an alternative hypothesis for the future. 
Sociological Review Monograph, 20(S1), 195-211.

Haug, M.R. (1988). A re-examination of the hypothesis of physician deprofessionalization. The Millbank Quarterly, 66(sup2), 48-56.

Heldal, F. (2010). Multidisciplinary collaboration as a loosely coupled system: integrating and blocking professional boundaries with objects. Journal of Interprofessional Care, 24(1), 19-30.

Holstein, J.A. \& Gubrium, J.F. (1995). The activeilnterview. London: Sage Publications.

Human Fertilisation and Embryology Authority. (2012a). A review of the HFEA's sperm and egg donation policies - 2011. Retrieved from http://www.hfea.gov.uk/docs/2011-0113 Donation review background.pdf

Human Fertilisation and Embryology Authority. (2012b). National donation strategy group. Retrieved from http://www.hfea.gov.uk/7138.html

Jonlin, E.C. (2015). The voices of the embryo donors. Trends in Molecular Medicine, 21(2), 55-57.

Kroeger, F. \& Bachmann, R. (2014). Trusting across boundaries. In J. Langan-Fox \& C.L. Cooper (Eds.), Boundary-spanning in organizations: network, influence, and conflict (pp. 253-284). New York: Routledge.

Kvale, S. (1996). Interviews. London: Sage Publications.

Langan-Fox, J. \& Cooper, C.L. (2014). Boundary-spanning in organizations: network, influence, and conflict. New York, NY: Routledge.

Lomax, G.P., \& Trounson, A.O., (2013). Correcting misperceptions about cryopreserved embryos and stem cell research. Nature Biotechnology, 31(4), 288-290.

Machin, L.L. (2011). A hierarchy of needs? Embryo donation, in vitro fertilisation and the provision of infertility counselling. Patient Education and Counselling, 85(2), 264-268.

Machin, L.L., Brown, N., \& McLeod, D. (2012). 'Two's company - three's a crowd': the collection of umbilical cord blood for commercial stem cell banks in England and the midwifery profession. Midwifery, 28(3), 358-365.

Mesler, M.A. (1991). Boundary encroachment and task delegation: clinical pharmacists on the medical team. Sociology of Health \& IIIness, 13(3), 310-331.

Monach, J. (2003). Counselling - its role in the infertility team. Human Fertility, 6(sup2), s17s21.

Pape, B., Thiessen, P.S., Jakobsen, F., \& Hansen, T.B. (2013). Interprofessional collaboration may pay off: introducing a collaborative approach in an orthopaedic ward. Journal of Interprofessional Care, 27(6), 496-500. 
Parry, S. (2006). (Re)constructing embryos in stem cell research: exploring the meaning of embryos for people involved in fertility treatments. Social Science \& Medicine, 62(10), 2349-2359.

Peng, Y., \& Sutanto, J. (2012). Facilitating knowledge sharing through a boundary spanner. IEEE Transactions on Professional Communication, 55(2), 142-155.

Provoost, V., Pennings, G., De Sutter, P., Gerris, J., Van de Velde, A., \& Dhont, M. (2010). Reflections by patients who undergo IVF on the use of their supernumerary embryos for science. Reproductive BioMedicine Online, 20(7), 880-891.

Provoost, V., Pennings, G., De Sutter, P., \& Dhont, M. (2012). A private matter: how patients decide what to do with cryopreserved embryos after infertility treatment. Human Fertility, 15(4), 210-216.

Reeves, S., Lewin, S., Espin, S., \& Zwarenstein, M. (2010). Interprofessional teamwork for health and social care. Oxford: Wiley-Blackwell.

Samorinha, C., Pereira, M., Machado, H., Figueiredo, B., \& Silva, S. (2014). Factors associated with the donation and non-donation of embryos for research: a systematic review. Human Reproduction Update, 20(5), 641-655.

Seale, C. \& Kelly, M. (1998). Coding and analysing data. In: C. Seale (Ed.), Researching society and c ulture (pp. $146-163$ ). London: Sage Publications.

Stephens, N., Atkinson, P., \& Glasner, P. (2008). The UK stem cell bank as performative architecture. New Genetics and Society, 27(2), 87-98.

Swedlow, B. (2007). Using the boundaries of science to do boundary-work among scientists: pollution and purity claims. Science and Public Policy, 34(9), 633-643.

Tellioglu, H, \& Wagner, I. (2001). Work practices surrounding PACS: the politics of space in hospitals. Computer Supported Cooperative Work, 10(2), 163-188.

Timmons, S., \& Tanner, J. (2004). A disputed occupational boundary: operating theatre nurses and operating department practitioners. Sociology of Health \& IIIness, 26(5), 645666.

van Zyl, C., van Dyk, A.C., \& Niemandt, C. (2005). The embryologist as counsellor during assisted reproduction procedures. Reproductive BioMedicine Online, 11(5), 545-551.

Wackerhausen, S. (2009). Collaboration, professional identity and reflection across boundaries. Journal of Interprofessional Care, 23(5), 455-473.

Wainwright, S.P., Williams, C., Michael, M., Farsides, B., \& Cribb, A. (2006). Ethical boundary-work in the embryonic stem cell laboratory. Sociology of Health \& IIIness, 28(6), 732-748.

Wilemon, D. (2014). Boundary-spanning as enacted in three organizational functions: new venture management, project management, and product management. In J. Langan-Fox 
\& C.L. Cooper (Eds.), Boundary-spanning in organizations: network, influence, and conflict (pp. 230-250). New York: Routledge.

Williams, P. (2011). The life and times of the boundary spanner. Journal of Integrated Care, 19(3), 26-33.

Williams, P. (2013). We are all boundary spanners now? International Journal of Public Sector Management, 26(1), 17-32. 